\title{
PROPOSAL FOR PERUVIAN STANDARD CONSIDERING THE EFFECT OF BIDIRECTIONALITY AND THE ANGLE OF INCIDENCE OF AN EARTHQUAKE
}

\author{
Edisson MOSCOSO ${ }^{1,2 *}$, Luis QUIROZ 1,2 \\ ${ }^{1}$ Civil Engineering Faculty, National University of Engineering, Lima, Peru. \\ ${ }_{2}^{2}$ Japan-Peru Center for Earthquake Engineering Research and Disaster Mitigation, Lima, Peru.
}

Received: 29/06/2019 Accepted: 07/08/2019

\begin{abstract}
Currently, it is assumed that seismic force applied to the building acts independently in two or three principal directions, orthogonal to each other, this assumption is not necessarily correct, because seismic analysis of buildings should consider the bidirectional effects of an earthquake. This consideration takes place if an angle of real incidence and the seismic force acting in each orthogonal direction is taken into account to estimate the maximum response of the building.

These effects will be analyzed by using the linear time-history analysis of 11 structures with different rigidities and eccentricities in two orthogonal directions, using angles of incidence each 10 degree and 20 Peruvian seismic records for rigid, intermediate and flexible soils obtained from database of Japan-Peru Center for Earthquake Engineering Research and Disaster Mitigation (CISMID) and Geophysical Institute of Peru (IGP). Furthermore, a non-linear time-history analysis will be carried out, which will be applied to one of the 11 structures and will use angles of incidence each 10 degree and one seismic record. The maximum seismic response will be compared with the maximum modal response spectral analysis obtaining a linear equation. to obtain a propose based on amplification factors.

Finally, amplification factors are proposed to obtain a relationship between modal spectral analysis and time-history analysis that consider the effects of the bidirectionality and the angle of incidence in reinforced concrete structures.
\end{abstract}

Keywords: Bidirectionality, Angle of incidence, Time-History Analysis.

\section{INTRODUCTION}

Peru is a highly seismic country and has many vulnerable buildings, making this a latent seismic risk throughout its territory, that has been heat in past earthquakes by the human and material losses.

Seismic forces are applied independently in two or three orthogonal principal directions to each other in the buildings, this assumption is not necessarily correct. The seismic analysis of buildings must consider bidirectionality (two directions that act simultaneously) and the angle of incidence (angle of the seismic action with the maximum response). [2]

International and national codes do not consider in detail the effects of the bidirectionality and angle of incidence on structural elements or overall structure.

In this article, the effects of bidirectionality and the angle of incidence on the response of a reinforced concrete structure will be analyzed and a procedure to consider them will be proposed.

Eleven (11) structures will be analyzed using lineal time history analysis and spectral modal analysis. From the 1st to the 6 th, their relative rigidity was varied in both directions, the 7th is irregular by "Reentrant Corner" and from the 8th to the 11th, varying its eccentricity (distance from the center of rigidity and mass). A nonlinear time history analysis of the 7th structure will also be performed. The maximum responses of these analyzes will be compared with those obtained from the spectral modal analysis. Its angle of incidence will be compared with that obtained from the direction perpendicular to that generated by the epicenter and the accelerometric station that registered its respective earthquake (this direction is from its shear wave). [6]

A procedure will be proposed to obtain an amplification factor that considers the effects of bidirectionality and the angle of incidence of the earthquake. This proposal considers relative rigidities and different eccentricities of the buildings.

\footnotetext{
${ }^{*}$ Corresponding author:

emoscosoa@uni.edu.pe
} 


\section{CRITERIA AND SELECTION PROCEDURE}

According to earthquake-resistant design principles, two levels of earthquakes, severe and moderate earthquakes, are currently defined. These levels will be defined according to their peak ground acceleration (PGA) considering a range of the selected records. Also, a low earthquake will be defined [7]:

Severe earthquakes: Earthquakes with a PGA greater than or equal to $200 \mathrm{~cm} / \mathrm{s}^{2}$.

Moderate earthquakes: Earthquakes with a PGA between $50 \mathrm{~cm} / \mathrm{s}^{2}$ and $200 \mathrm{~cm} / \mathrm{s}^{2}$.

Low earthquakes: Earthquakes with a PGA less than or equal to $50 \mathrm{~cm} / \mathrm{s}^{2}$.

For the selection of seismic records, the most severe and moderate earthquake will be chosen, these being representative.

A soil type has also been identified for each accelerometer station of the Accelerometers Network of CISMID (REDACIS) and accelerometers stations of IGP, in accordance with the E.030 standard:

Type S1 Profile: Rock or Rigid Soils

Type S2 Profile: Intermediate Soils

Type S3 Profile: Soft Soils

The soil types of the stations located in Lima and Callao were identified according to the seismic microzoning included in REDACIS. The other stations were identified according to the microzoning carried out by CISMID and other entities (Ica, Arequipa, Moquegua, Tacna and Moyobamba).

For the process of selecting seismic records, those with a larger PGA in one of their horizontal directions were chosen (the vertical direction is omitted in this study).

For stations with a type of Soil S1 (Rock or Rigid Soils), it has the highest number of severe and moderate records in REDACIS, so 5 historical seismic records (year 1966, 1970 and 1974) and 5 actual records (from 2005 to 2012) were chosen (see Table 1 y 2).

For stations with a soil type S2 (Intermediate Soil), the sample of 5 seismic records, corresponding to severe and moderate analyses, 4 of them from REDACIS and 1 IGP record, were chosen (see Table 3).

For stations with a type of S3 Soil (Soft Soil), due to the available information, a sample of 5 seismic records, corresponding to moderate and low records, 2 of them from the REDACIS and 3 IGP records, were chosen (see Table 4).

Table 1. Peak Ground Acceleration (PGA) of earthquakes in soil type $\mathrm{S} 1$ (Historical records)

\begin{tabular}{|c|c|c|c|c|c|c|c|c|c|}
\hline \multicolumn{10}{|c|}{ PGA OF EARTHQUAKES IN SOIL TYPE S1 - HISTORICAL RECORDS (gal) - REDACIS } \\
\hline \multicolumn{4}{|c|}{ EARTHQUAKES } & \multirow{2}{*}{\multicolumn{2}{|c|}{$\begin{array}{l}\text { “PARQUE DE LA } \\
\text { RESERVA”(S1) }\end{array}$}} & \multirow{2}{*}{\multicolumn{2}{|c|}{$\begin{array}{l}\text { “ZARATE" } \\
\text { (S1) }\end{array}$}} & \multirow{2}{*}{\multicolumn{2}{|c|}{$\begin{array}{c}\text { "LA MOLINA - UNIV. } \\
\text { AGRARIA" } \\
(\mathrm{S} 1)\end{array}$}} \\
\hline \multirow{2}{*}{ RECORD } & \multirow{2}{*}{ DATE } & \multirow{2}{*}{ MAGNITUDE } & \multirow{2}{*}{ DEPTH } & & & & & & \\
\hline & & & & EW & NS & EW & NS & EW & NS \\
\hline $\mathrm{S}_{1 \mathrm{H}-1}$ & 17-Oct-66 & $8.1 \mathrm{Mw}$ & $24.00 \mathrm{~km}$ & 180.56 & 268.24 & & & & \\
\hline $\mathrm{S} 1 \mathrm{H}-2$ & 3-Oct-74 & $6.6 \mathrm{mb}$ & $13.00 \mathrm{~km}$ & 194.21 & 180.09 & & & & \\
\hline $\mathrm{S} 1 \mathrm{H}-3$ & 5-Ene-74 & $6.1 \mathrm{mb}$ & $91.70 \mathrm{~km}$ & 66.72 & 71.63 & 138.94 & 156.3 & & \\
\hline $\mathrm{S} 1 \mathrm{H}-4$ & 9-Nov-74 & $6.0 \mathrm{mb}$ & $12.80 \mathrm{~km}$ & 46.28 & 69.96 & & & 117.08 & 93.56 \\
\hline $\mathrm{S} 1 \mathrm{H}-5$ & 31-May-70 & $6.6 \mathrm{Mb}$ & $64.00 \mathrm{~km}$ & 105.05 & 97.81 & & & & \\
\hline
\end{tabular}

Table 2. Peak Ground Acceleration (PGA) of earthquakes in soil type S1 (Actual records)

\begin{tabular}{|c|c|c|c|c|c|c|c|c|c|}
\hline \multicolumn{10}{|c|}{ PGA OF EARTHQUAKES IN SOIL TYPE S1 - ACTUAL RECORDS (gal) - REDACIS E IGP } \\
\hline \multicolumn{4}{|c|}{ EARTHQUAKES } & \multirow{2}{*}{\multicolumn{2}{|c|}{$\begin{array}{l}\text { “TACNA-UNIV. } \\
\text { BASADRE" (S1) }\end{array}$}} & \multirow{2}{*}{\multicolumn{2}{|c|}{$\begin{array}{l}\text { "TACNA-UNIV. } \\
\text { PRIVADA" (S1) }\end{array}$}} & \multirow{2}{*}{\multicolumn{2}{|c|}{$\begin{array}{l}\text { "AREQUIPA - INST. } \\
\text { GEOF. CHARACATO" } \\
\left(\mathrm{S}_{1}\right)\end{array}$}} \\
\hline \multirow{2}{*}{ RECORD } & \multirow{2}{*}{ DATE } & \multirow{2}{*}{ MAGNITUDE } & \multirow{2}{*}{ DEPTH } & & & & & & \\
\hline & & & & EW & NS & EW & NS & EW & NS \\
\hline S1A-1 & 5-May-10 & $6.5 \mathrm{ML}$ & $36.00 \mathrm{~km}$ & 154 & 190 & 99.7 & 104 & & \\
\hline S1A-2 & 14-May-12 & $6.1 \mathrm{ML}$ & $98.00 \mathrm{~km}$ & & & 180 & 85.6 & & \\
\hline S1A-3 & 13-Jun-05 & $7.2 \mathrm{ML}$ & $146.00 \mathrm{~km}$ & 85.54 & 94.18 & & & 138.5 & 125.43 \\
\hline S1A-4 & 13-Jun-05 & $7.2 \mathrm{ML}$ & $146.00 \mathrm{~km}$ & 85.54 & 94.18 & 119.11 & 111.2 & & \\
\hline S1A-5 & 5-May-10 & $6.5 \mathrm{ML}$ & $36.00 \mathrm{~km}$ & 154 & 190 & 99.7 & 104 & & \\
\hline
\end{tabular}


Table 3. Peak Ground Acceleration (PGA) of earthquakes in soil type S2

\begin{tabular}{|c|c|c|c|c|c|c|c|c|c|c|c|}
\hline \multicolumn{12}{|c|}{ PGA OF EARTHQUAKES IN SOIL TYPE S2 - HISTORICAL RECORDS - (gal) - REDACIS E IGP } \\
\hline \multicolumn{4}{|c|}{ EARTHQUAKES } & \multirow{2}{*}{\multicolumn{2}{|c|}{$\begin{array}{c}\text { "ICA - UNIV. SAN } \\
\text { LUIS GONZAGA" } \\
\left(\mathrm{S}_{2}\right)\end{array}$}} & \multirow{2}{*}{\multicolumn{2}{|c|}{$\begin{array}{l}\text { "MOQUEGUA } \\
\text { VIZCARRA" } \\
\left(S_{2}\right)\end{array}$}} & \multirow{2}{*}{\multicolumn{2}{|c|}{$\begin{array}{c}\text { "AREQUIPA - } \\
\text { UNIV. SAN } \\
\text { AGUSTÍN"(S2) }\end{array}$}} & \multirow{2}{*}{\multicolumn{2}{|c|}{$\begin{array}{l}\text { “LA YARADA- } \\
\text { IGP”(S2) }\end{array}$}} \\
\hline \multirow{2}{*}{ RECORD } & \multirow{2}{*}{ DATE } & \multirow{2}{*}{ MAGNITUDE } & \multirow{2}{*}{ DEPTH } & & & & & & & & \\
\hline & & & & EW & NS & EW & NS & EW & NS & EW & NS \\
\hline S2-1 & 15-Ago-07 & $7.0 \mathrm{ML}$ & $40.00 \mathrm{~km}$ & 272.82 & 333.66 & & & & & & \\
\hline S2-2 & 23-Jun-01 & $6.9 \mathrm{mb}$ & $33.00 \mathrm{~km}$ & & & 295.15 & 220 & & & & \\
\hline S2-3 & 6-May-10 & $6.5 \mathrm{ML}$ & $36.00 \mathrm{~km}$ & & & & & & & 182.65 & 94.14 \\
\hline S2-4 & 7-Jul-01 & $6.5 \mathrm{mb}$ & $33.00 \mathrm{~km}$ & & & & & 123.21 & 120.52 & & \\
\hline S2-5 & 13-Jun-05 & $7.2 \mathrm{ML}$ & $146.00 \mathrm{~km}$ & & & & & 80.92 & 65.12 & & \\
\hline
\end{tabular}

Table 4. Peak Ground Acceleration (PGA) of earthquakes in soil type S3

\begin{tabular}{|c|c|c|c|c|c|c|c|c|c|c|c|c|c|}
\hline \multicolumn{14}{|c|}{ PGA OF EARTHQUAKES IN SOIL TYPE S3 - HISTORICAL RECORDS - (gal) - REDACIS E IGP } \\
\hline \multicolumn{4}{|c|}{ EARTHQUAKES } & \multirow{2}{*}{\multicolumn{2}{|c|}{$\begin{array}{l}\text { “CALLAO - } \\
\text { DHN”(S3) }\end{array}$}} & \multirow{2}{*}{\multicolumn{2}{|c|}{$\begin{array}{c}\text { “МоУовАМВА" } \\
\left(\mathrm{S}_{3}\right)\end{array}$}} & \multirow{2}{*}{\multicolumn{2}{|c|}{$\begin{array}{l}\text { “JABONILLOS - } \\
\text { IGP” (S3) }\end{array}$}} & \multirow{2}{*}{\multicolumn{2}{|c|}{$\begin{array}{c}\text { “TARAPOTO - } \\
\text { IGP” (S3) }\end{array}$}} & \multirow{2}{*}{\multicolumn{2}{|c|}{$\begin{array}{l}\text { “PUCALLPA- } \\
\text { IGP” (S3) }\end{array}$}} \\
\hline \multirow{2}{*}{ RECORD } & \multirow{2}{*}{ DATE } & \multirow{2}{*}{ MAGNITUDE } & \multirow{2}{*}{ DEPTH } & & & & & & & & & & \\
\hline & & & & EW & NS & EW & NS & EW & NS & EW & NS & EW & NS \\
\hline$S_{3-1}$ & 24-Ago-11 & $7.0 \mathrm{ML}$ & $148.00 \mathrm{~km}$ & & & & & 199.38 & 98.11 & & & & \\
\hline S3-2 & 24-Ago-11 & $7.0 \mathrm{ML}$ & $148.00 \mathrm{~km}$ & & & & & & & 158.9 & 157.3 & & \\
\hline S3-3 & 25-Set-05 & $7.0 \mathrm{ML}$ & $115.00 \mathrm{~km}$ & & & 131.36 & 103.4 & & & & & & \\
\hline S3-4 & 15-Ago-07 & $7.0 \mathrm{ML}$ & $40.00 \mathrm{~km}$ & 101.0 & 95.7 & & & & & & & & \\
\hline
\end{tabular}

\section{STRUCTURES AND ANGLES OF INCIDENCE ANALYZED}

Eleven (11) types of structures were analyzed using linear Time-History Analysis with 20 seismic records mentioned above.

The analysis of time-history structures was linear (it did not consider the non-linearity of its materials, geometric or P-Delta). This allowed to increase the amount of analysis to be performed in records as in angles of incidence. The angles of incidence were used every 10 degrees, from 0 to 350 degrees and 20 seismic records mentioned above. This implies that for 20 seismic records there are 720 models per structure and in total 7920 structural models considered in the investigation.

In addition, a nonlinear time-history analysis in an irregular structure (seventh structure) was analyzed. This considered the nonlinearity of the materials. The angles of incidence were every 10 degrees (from 0 to 350 degrees) and a representative seismic record $\left(\mathrm{S}_{1} \mathrm{H}_{1}\right.$, see Table 1). This implies 36 non-linear structural models. This was applied to verify the angle of incidence compared to the linear response.

\section{DESCRIPTION, ANALYSIS AND RESPONSE OF STRUCTURES}

The eleven structures contain changes in lateral stiffness, changes in eccentricity and irregularity by "Reentrant Corner" in both directions. Six structures have zero eccentricity, that is, their center of mass and center of stiffness coincide in the same coordinate. The structural walls of reinforced concrete in the $Y-Y$ direction were considered to increase the stiffness in this direction and that the stiffness in the $\mathrm{X}-\mathrm{X}$ direction did not change. The seventh structure has a moment resisting frame structural system, zero eccentricity, same rigidity and irregular by "Reentrant Corner" in both directions. The other four structures have a moment resisting frame structural system, in which their eccentricity increases but they are the same in both directions. They have the same rigidity in both directions too (see Figure 1). 


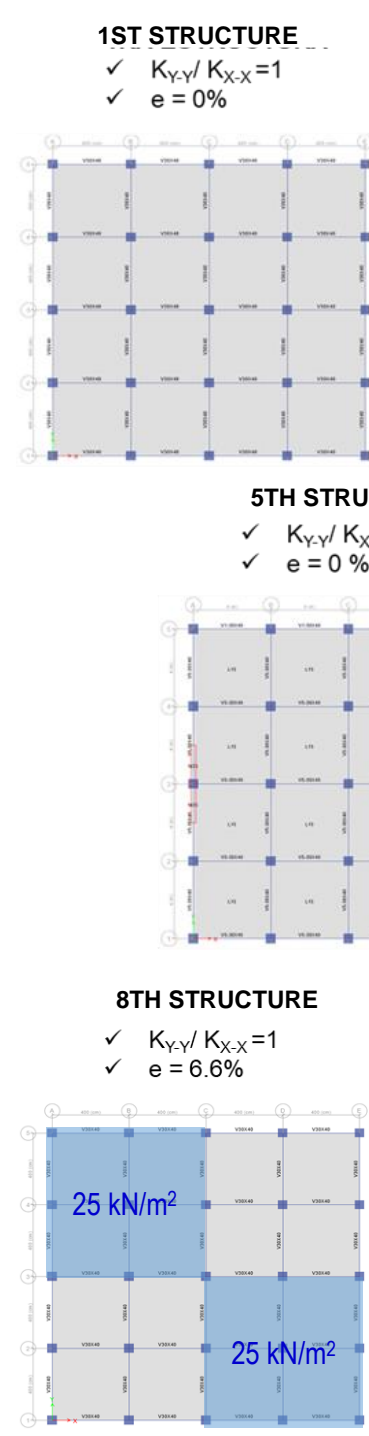

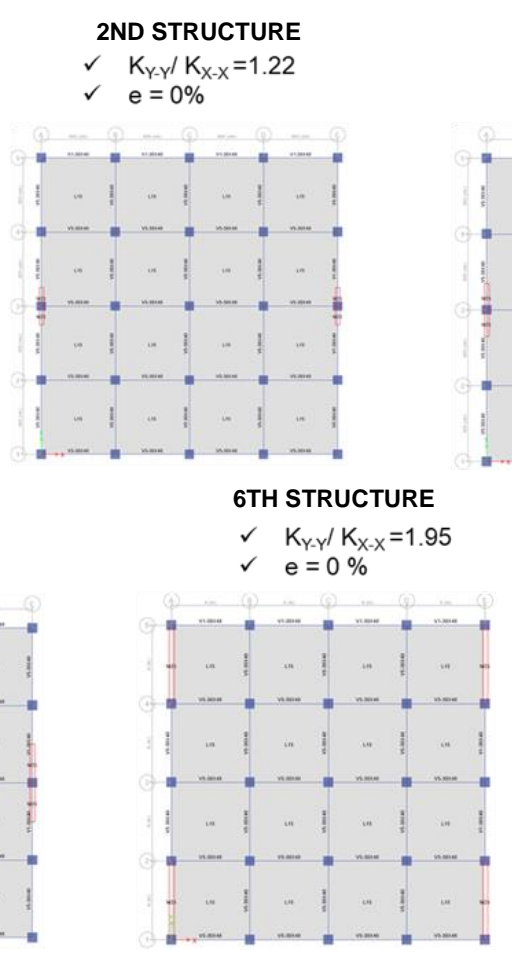
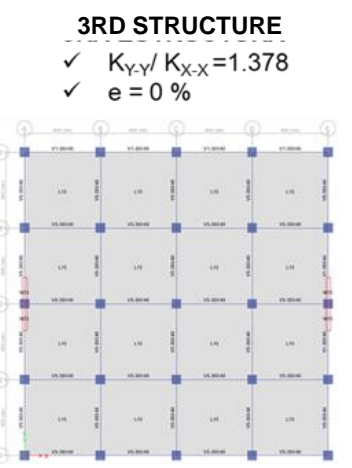

7TH STRUCTURE

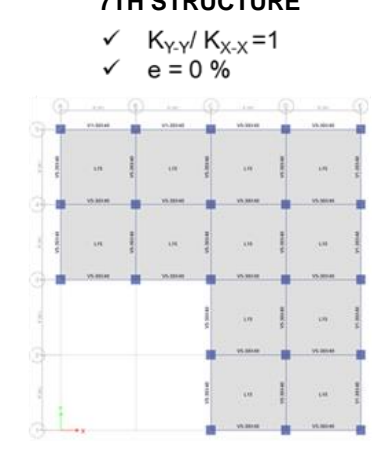

10TH STRUCTURE

9TH STRUCTURE

$\begin{array}{ll}\checkmark & K_{Y-Y} / K_{X-X}=1 \\ \checkmark & e=13.3 \%\end{array}$

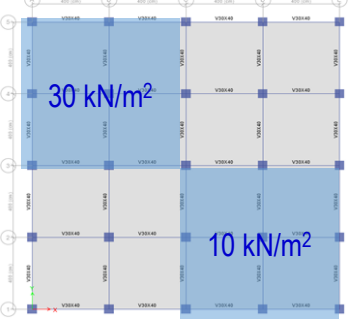

$\checkmark \quad K_{Y-Y} / K_{X-X}=1$

$\checkmark \quad e=20 \%$

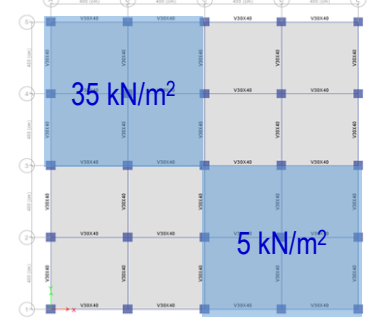

4TH STRUCTURE
$\checkmark \mathrm{K}_{\mathrm{Y}-\mathrm{Y}} / \mathrm{K}_{\mathrm{X}-\mathrm{X}}=1.55$
$\checkmark$

$\checkmark \quad \mathrm{e}=0 \%$

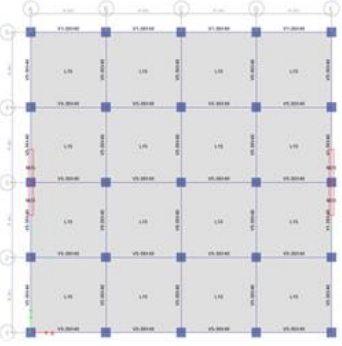

Figure 1. Structural models with different lateral stiffness (1st to 6th), irregularity by "reentrant corner" (7th) and different relative eccentricity (8th to 11th)

A summary of the results will be shown below. For example, Figures 2 and 3 show the summary of the results obtained from the analyses for structure 1 . These indicate the percentage ratio between the response obtained by the linear history time analysis (RATHL) considering the bidirectionality and angle of incidence and the response by the spectral modal analysis (RAME) for each of the 20 seismic records considered. Similarly, the results have been obtained for all structures including the 7th Structure which was performed a nonlinear time-history analysis in order to compare the results, see Figure 5. 

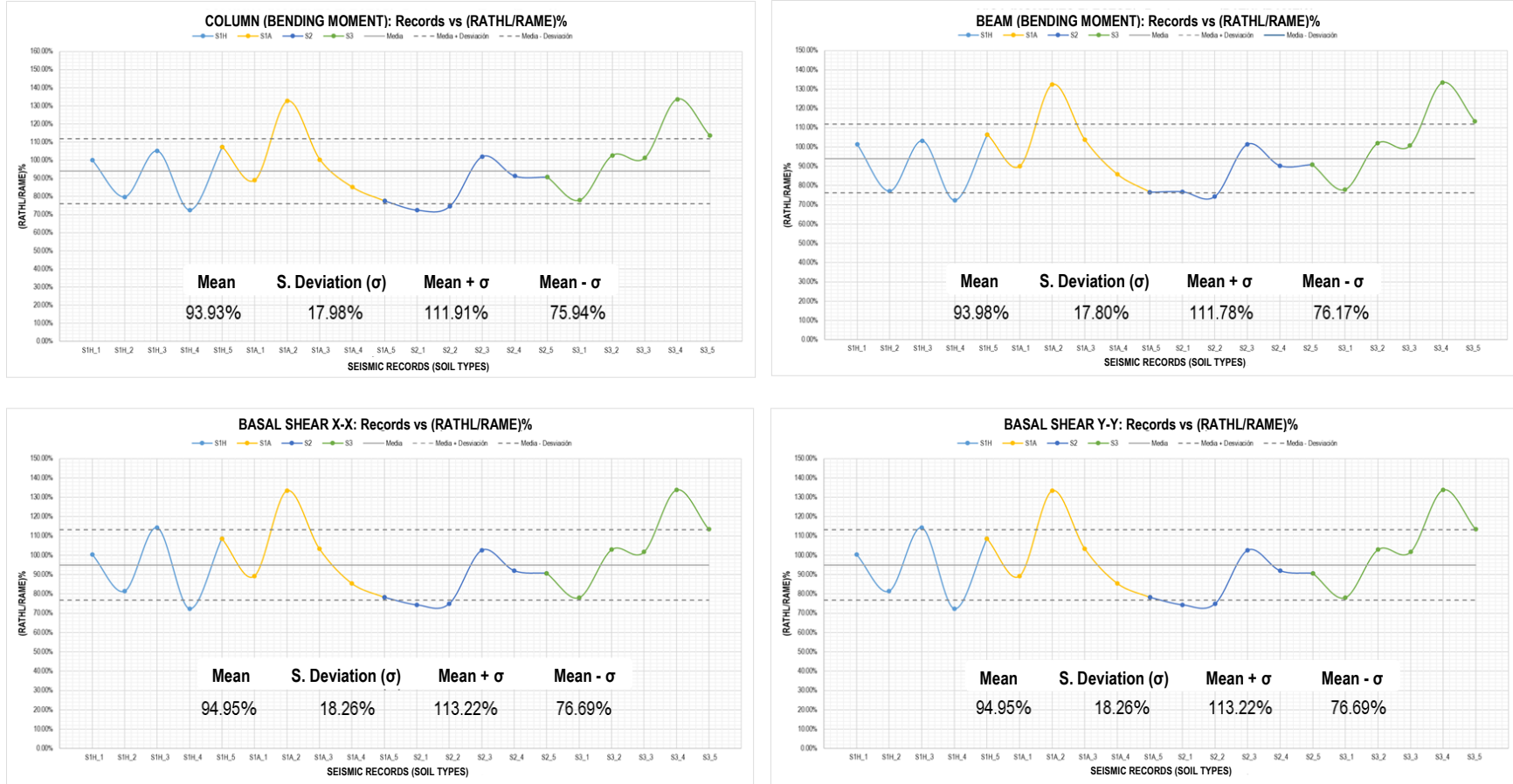

Figure 2. Mean and Standard Deviation of the percentages of comparison between the responses of ATHL and AME - 1st structure (1st part)
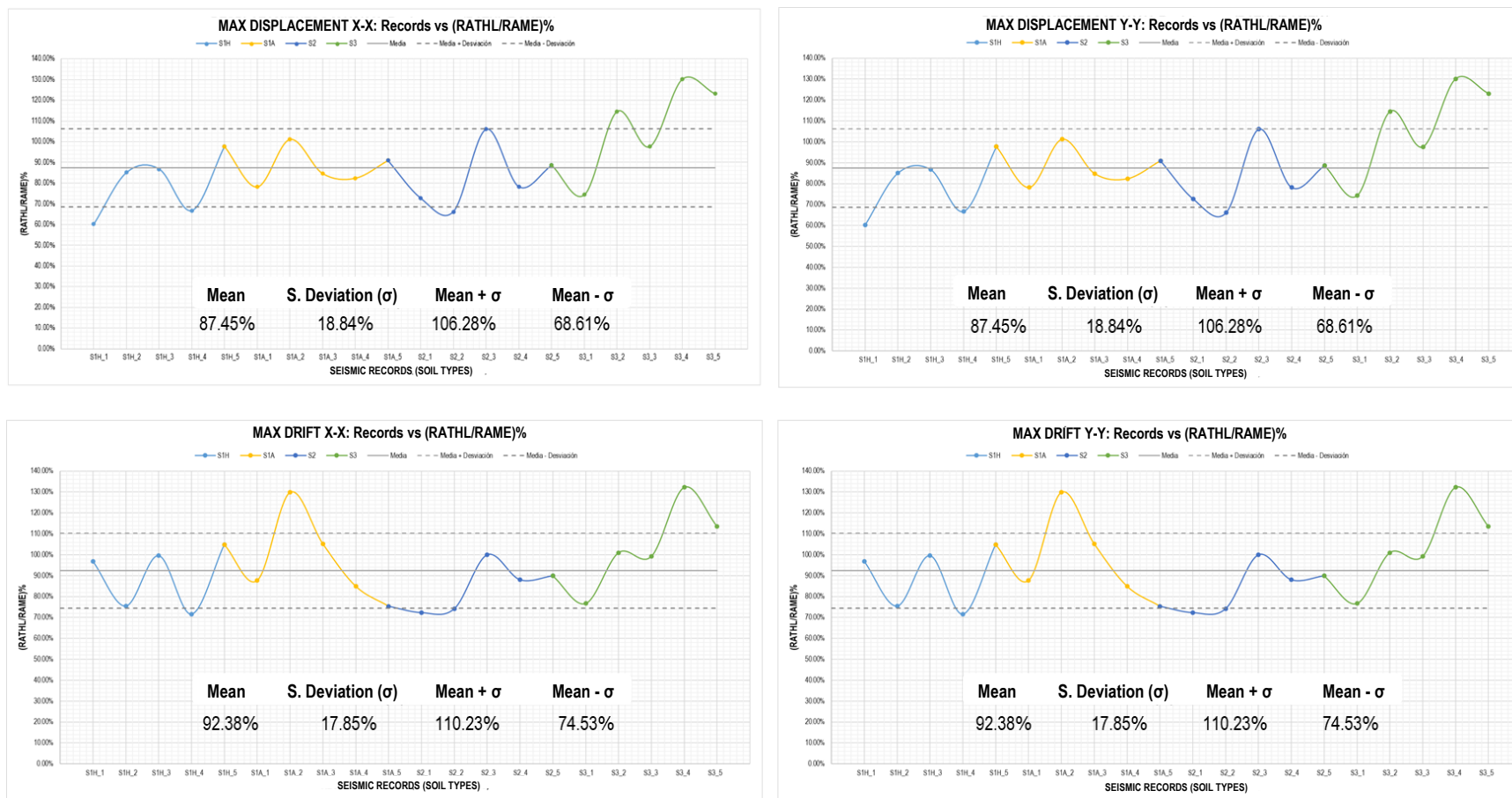

Figure 3. Mean and Standard Deviation of the percentages of comparison between the responses of ATHL and AME - 1st structure (2nd part) 


\section{LEVELS OF THE ANGLES OF INCIDENCE}

The results of the angles of incidence have been graded according to their coincidence with the perpendicular angles generated from the location of the epicenter of an earthquake and the accelerometric station that recorded it, as well as an example see Figure 4. This was done by locating both the coordinates of the epicenter of the earthquake and those of the accelerometric stations, and then draw a line between these points and determine the angle between them.
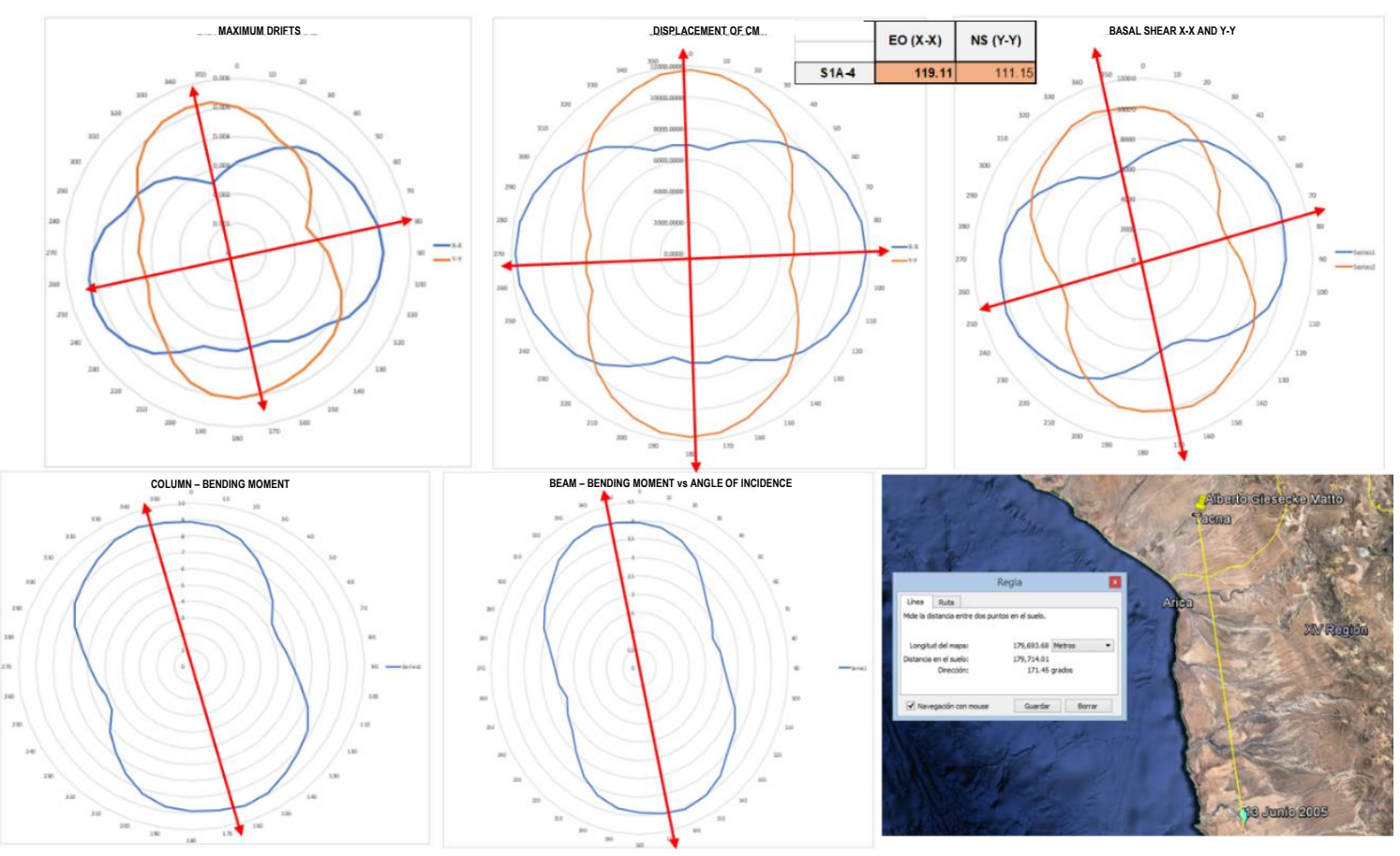

Figure 4. Variation in the structural response with respect to the angle of incidence and perpendicular direction formed by the epicenter of the earthquake and the accelerometric station that registered it (yellow line) - 1st Structure - S1A4

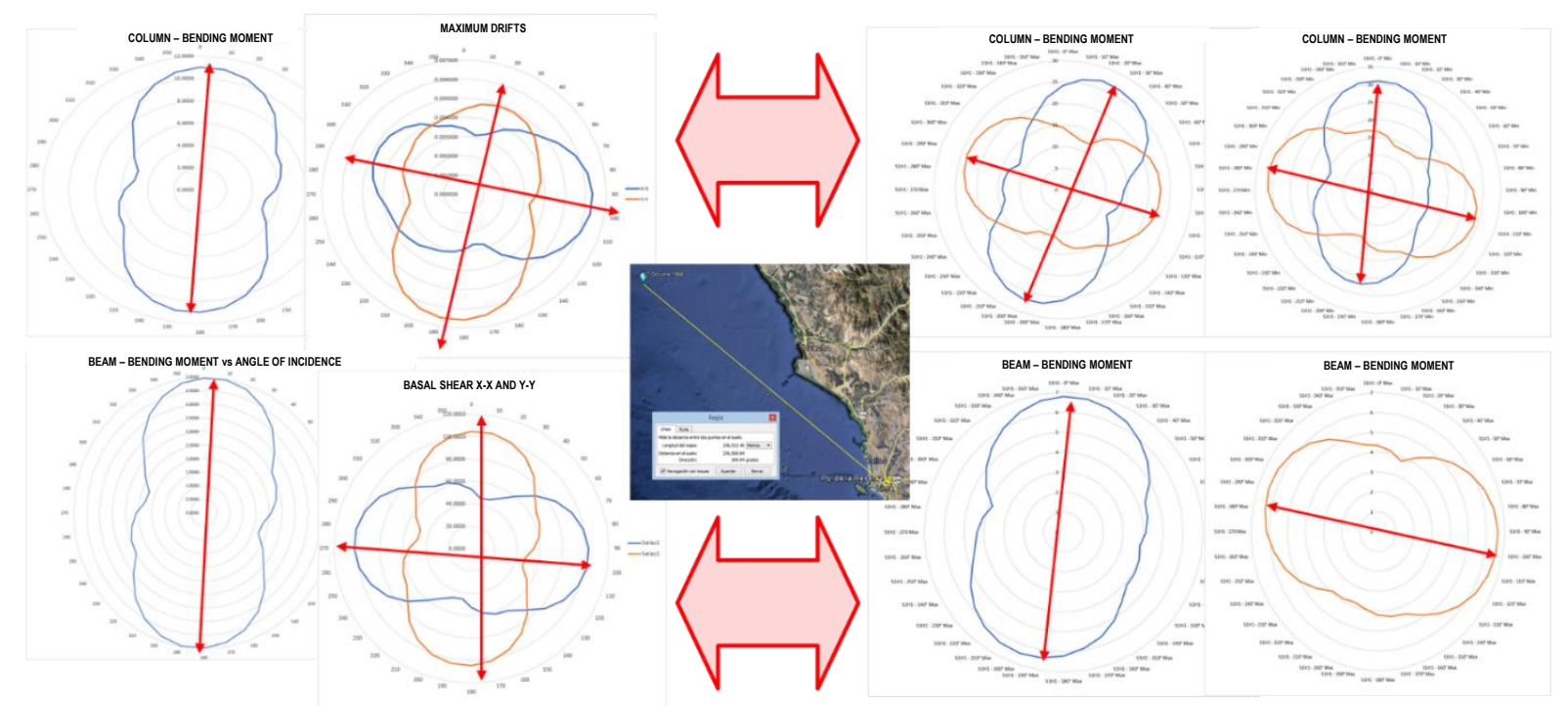

Figure 5. Comparison of the variation in the structural response with respect to the angle of incidence and perpendicular direction formed by the epicenter of the earthquake and the accelerometric station that registered it (yellow line) for the linear and non-linear analysis 
Table 5. Number of matching levels by soil type and structure

\begin{tabular}{|c|c|c|c|}
\cline { 2 - 4 } \multicolumn{1}{c|}{} & \multicolumn{3}{c|}{ 1st Structure } \\
\cline { 3 - 4 } \multicolumn{1}{c|}{} & High & Intermediate & Low \\
\hline S1H & 4 & 0 & 1 \\
\cline { 1 - 1 } S1A & 4 & 0 & 1 \\
\cline { 1 - 2 } S2 & 2 & 1 & 2 \\
\hline S3 & 3 & 0 & 2 \\
\hline TOTAL & 13 & 1 & 6 \\
\hline & $\mathbf{6 5 . 0 0 \%}$ & $\mathbf{5 . 0 0 \%}$ & $\mathbf{3 0 . 0 0 \%}$ \\
\hline
\end{tabular}

\begin{tabular}{|c|c|c|c|}
\hline & \multicolumn{3}{|c|}{ 5th Structure } \\
\hline & High & Intermediate & Low \\
\hline S1H & 2 & 3 & 0 \\
\hline S1A & 0 & 4 & 1 \\
\hline S2 & 2 & 2 & 1 \\
\hline S3 & 3 & 2 & 0 \\
\hline TOTAL & 7 & 11 & 2 \\
\hline & $35.00 \%$ & $55.00 \%$ & $10.00 \%$ \\
\hline
\end{tabular}

\begin{tabular}{|c|c|c|c|}
\cline { 2 - 4 } \multicolumn{1}{c|}{} & \multicolumn{3}{c|}{ 9th Structure } \\
\cline { 2 - 4 } \multicolumn{1}{c|}{} & High & Intermediate & Low \\
\hline S1H & 1 & 4 & 0 \\
\cline { 1 - 1 } S1A & 0 & 4 & 1 \\
\cline { 1 - 1 } S2 & 3 & 2 & 0 \\
\hline S3 & 3 & 1 & 1 \\
\hline TOTAL & 7 & 11 & 2 \\
\hline & $\mathbf{3 5 . 0 0 \%}$ & $\mathbf{5 5 . 0 0 \%}$ & $\mathbf{1 0 . 0 0 \%}$ \\
\hline
\end{tabular}

\begin{tabular}{|c|c|c|c|}
\cline { 2 - 4 } \multicolumn{1}{c|}{} & \multicolumn{3}{c|}{ 2nd Structure } \\
\cline { 2 - 4 } \multicolumn{1}{c|}{} & High & Intermediate & Low \\
\hline S1H & 2 & 3 & 0 \\
\cline { 1 - 3 } S1A & 4 & 1 & 0 \\
\cline { 1 - 3 } S2 & 1 & 4 & 0 \\
\hline S3 & 3 & 1 & 1 \\
\hline TOTAL & 10 & 9 & 1 \\
\hline & $\mathbf{5 0 . 0 0 \%}$ & $\mathbf{4 5 . 0 0 \%}$ & $\mathbf{5 . 0 0 \%}$ \\
\hline
\end{tabular}

\begin{tabular}{|c|c|c|c|}
\cline { 2 - 4 } \multicolumn{1}{c|}{} & \multicolumn{3}{c|}{ 6th Structure } \\
\cline { 2 - 4 } \multicolumn{1}{c|}{} & High & Intermediate & Low \\
\hline S1H & 0 & 2 & 3 \\
\cline { 1 - 1 } S1A & 2 & 2 & 1 \\
\cline { 1 - 2 } S2 & 2 & 2 & 1 \\
\hline S3 & 2 & 2 & 1 \\
\hline TOTAL & 6 & 8 & 6 \\
\hline & $\mathbf{3 0 . 0 0 \%}$ & $\mathbf{4 0 . 0 0 \%}$ & $\mathbf{3 0 . 0 0 \%}$ \\
\cline { 3 - 5 } & & &
\end{tabular}

\begin{tabular}{|c|c|c|c|}
\cline { 2 - 4 } \multicolumn{1}{c|}{} & \multicolumn{3}{c|}{ 10th Structure } \\
\cline { 2 - 4 } & High & Intermediate & Low \\
\hline S1H & 1 & 4 & 0 \\
\hline S1A & 0 & 5 & 0 \\
\cline { 1 - 1 } S2 & 2 & 3 & 0 \\
\hline S3 & 3 & 2 & 0 \\
\hline TOTAL & 6 & 14 & 0 \\
\hline \multicolumn{1}{|c|}{} & $\mathbf{3 0 . 0 0 \%}$ & $\mathbf{7 0 . 0 0 \%}$ & $\mathbf{0 . 0 0 \%}$ \\
\hline
\end{tabular}

\begin{tabular}{|c|c|c|c|}
\cline { 2 - 4 } \multicolumn{1}{c|}{} & \multicolumn{3}{c|}{ 3rd Structure } \\
\cline { 2 - 4 } \multicolumn{1}{c|}{} & High & Intermediate & Low \\
\hline S1H & 3 & 1 & 1 \\
\cline { 1 - 3 } S1A & 3 & 2 & 0 \\
\hline S2 & 1 & 4 & 0 \\
\hline S3 & 2 & 3 & 0 \\
\hline TOTAL & 9 & 10 & 1 \\
\hline & $\mathbf{4 5 . 0 0 \%}$ & $\mathbf{5 0 . 0 0 \%}$ & $\mathbf{5 . 0 0} \%$ \\
\hline
\end{tabular}

\begin{tabular}{|c|c|c|c|}
\cline { 2 - 4 } \multicolumn{1}{c|}{} & \multicolumn{3}{c|}{ 7th Structure } \\
\cline { 2 - 4 } & High & Intermediate & Low \\
\hline S1H & 2 & 2 & 1 \\
S1A & 4 & 0 & 1 \\
\cline { 1 - 1 } S2 & 2 & 3 & 0 \\
\hline S3 & 3 & 2 & 0 \\
\hline TOTAL & 11 & 7 & 2 \\
\hline & $\mathbf{5 5 . 0 0 \%}$ & $\mathbf{3 5 . 0 0 \%}$ & $\mathbf{1 0 . 0 0 \%}$ \\
\hline
\end{tabular}

\begin{tabular}{|c|c|c|c|}
\cline { 2 - 4 } \multicolumn{1}{c|}{} & \multicolumn{3}{c|}{ 11th Structure } \\
\cline { 2 - 4 } & High & Intermediate & Low \\
\hline S1H & 1 & 3 & 1 \\
\hline S1A & 2 & 3 & 0 \\
\hline S2 & 1 & 3 & 1 \\
\hline S3 & 2 & 3 & 0 \\
\hline TOTAL & 6 & 12 & 2 \\
\hline & $\mathbf{3 0 . 0 0 \%}$ & $\mathbf{6 0 . 0 0 \%}$ & $\mathbf{1 0 . 0 0 \%}$ \\
\hline
\end{tabular}

\begin{tabular}{|c|c|c|c|}
\cline { 2 - 4 } \multicolumn{1}{c|}{} & \multicolumn{3}{c|}{ 4th Structure } \\
\cline { 2 - 4 } \multicolumn{1}{c|}{} & High & Intermediate & Low \\
\hline S1H & 2 & 2 & 1 \\
\hline S1A & 1 & 3 & 1 \\
\cline { 1 - 2 } S2 & 1 & 3 & 1 \\
\hline S3 & 3 & 1 & 1 \\
\hline TOTAL & 7 & 9 & 4 \\
\hline & $35.00 \%$ & $\mathbf{4 5 . 0 0 \%}$ & $\mathbf{2 0 . 0 0 \%}$ \\
\hline
\end{tabular}

\begin{tabular}{|c|c|c|c|}
\cline { 2 - 4 } \multicolumn{1}{c|}{} & \multicolumn{3}{c|}{ 8th Structure } \\
\cline { 2 - 4 } \multicolumn{1}{c|}{} & High & Intermediate & Low \\
\hline S1H & 2 & 3 & 0 \\
\hline S1A & 2 & 2 & 1 \\
\hline S2 & 1 & 4 & 0 \\
\hline S3 & 3 & 1 & 1 \\
\hline TOTAL & 8 & 10 & 2 \\
\hline & $\mathbf{4 0 . 0 0 \%}$ & $\mathbf{5 0 . 0 0 \%}$ & $\mathbf{1 0 . 0 0 \%}$ \\
\cline { 3 - 5 } & & &
\end{tabular}

\begin{tabular}{|c|c|c|c|}
\cline { 2 - 4 } \multicolumn{1}{c|}{} & \multicolumn{3}{c|}{ Application } \\
\cline { 2 - 4 } & High & Intermediate & Low \\
\hline S1H & 1 & 4 & 0 \\
\hline S1A & 2 & 3 & 0 \\
\hline S2 & 3 & 2 & 0 \\
\hline S3 & 2 & 2 & 1 \\
\hline TOTAL & 8 & 11 & 1 \\
\hline & $\mathbf{4 0 . 0 0 \%}$ & $55.00 \%$ & $\mathbf{5 . 0 0 \%}$ \\
\hline
\end{tabular}

\section{BIDIRECTIONAL AMPLIFICATION FACTOR AND ANGLE OF INCIDENCE}

Depending on the rigidity in both directions, the structures from 1 to 6 have been proposed and according to the eccentricity (equal in both directions) the structures from 8 to 11 have been proposed. Structure 7 is to consider a structure with different irregularity than the above.
To have a correct level of reliability, the response that the structure might have has been considered as the one obtained from the mean plus a standard deviation. Thus, for each structure it has been considered a rule that is a linear formulation for obtaining amplification factors either by rigidity or by eccentricity. 
Table 6. Structure response according to stiffness ratio

\begin{tabular}{|c|c|c|c|c|c|c|}
\hline Structure & Ky-y/kx-x & Mean & Deviation $(\boldsymbol{\sigma})$ & Mean $+\boldsymbol{\sigma}$ & Mean - $\boldsymbol{\sigma}$ & Amplification \\
\hline 1 & 1 & $92.14 \%$ & $18.21 \%$ & $110.36 \%$ & $73.90 \%$ & 1.1036 \\
2 & 1.22 & $95.08 \%$ & $18.48 \%$ & $113.61 \%$ & $76.52 \%$ & 1.1361 \\
3 & 1.38 & $96.58 \%$ & $19.13 \%$ & $115.78 \%$ & $77.33 \%$ & 1.1578 \\
4 & 1.55 & $98.99 \%$ & $25.12 \%$ & $124.70 \%$ & $72.85 \%$ & 1.247 \\
5 & 1.72 & $100.44 \%$ & $26.86 \%$ & $128.12 \%$ & $72.14 \%$ & 1.2812 \\
6 & 1.95 & $98.73 \%$ & $29.86 \%$ & $129.63 \%$ & $66.98 \%$ & 1.2963 \\
\hline
\end{tabular}

Table 7. Structure response according to eccentricity

\begin{tabular}{|c|c|c|c|c|c|c|}
\hline Structure & e (\%) & Mean & Deviation ( $\sigma)$ & Mean + $\boldsymbol{\sigma}$ & Mean - $\boldsymbol{\sigma}$ & Amplification \\
\hline 1 & $0.0 \%$ & $92.14 \%$ & $18.21 \%$ & $110.36 \%$ & $73.90 \%$ & 1.1036 \\
8 & $6.6 \%$ & $95.36 \%$ & $18.50 \%$ & $113.89 \%$ & $76.82 \%$ & 1.1389 \\
9 & $13.3 \%$ & $107.95 \%$ & $22.46 \%$ & $130.43 \%$ & $85.45 \%$ & 1.3043 \\
10 & $20.0 \%$ & $117.83 \%$ & $26.71 \%$ & $144.61 \%$ & $91.01 \%$ & 1.4461 \\
11 & $26.6 \%$ & $122.69 \%$ & $28.22 \%$ & $151.05 \%$ & $94.23 \%$ & 1.5105 \\
\hline
\end{tabular}

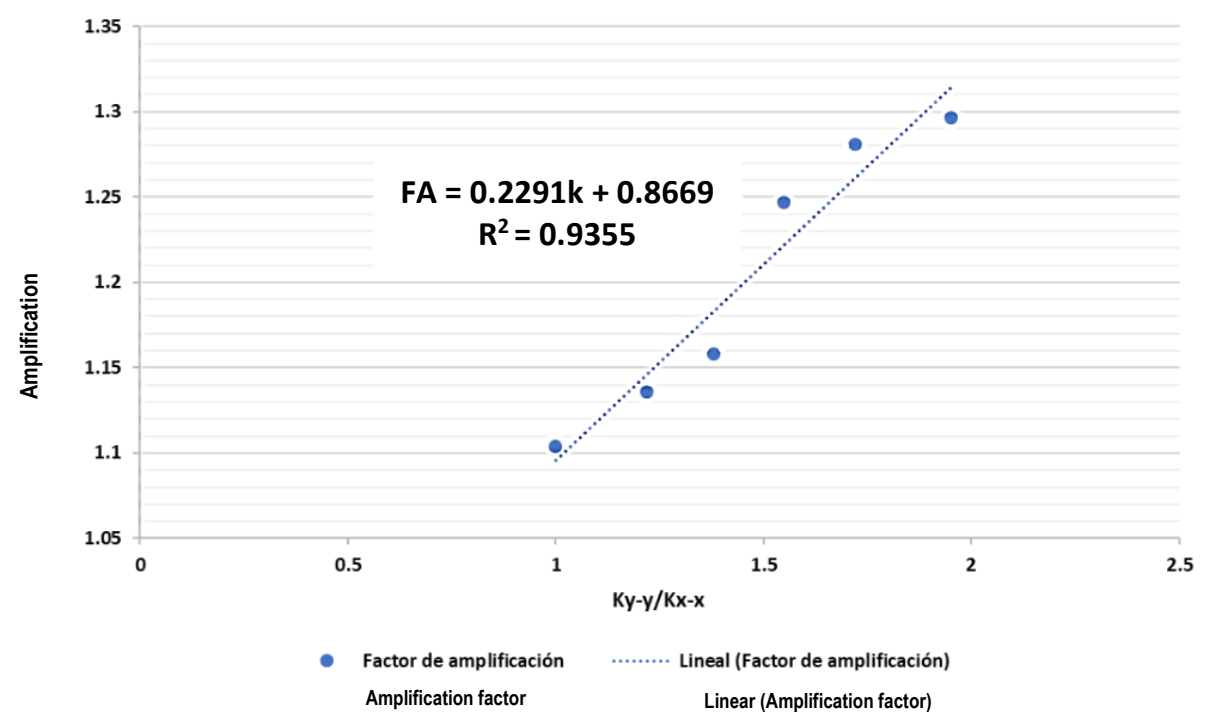

Figure 6. Rule for obtaining the amplification factor by stiffness

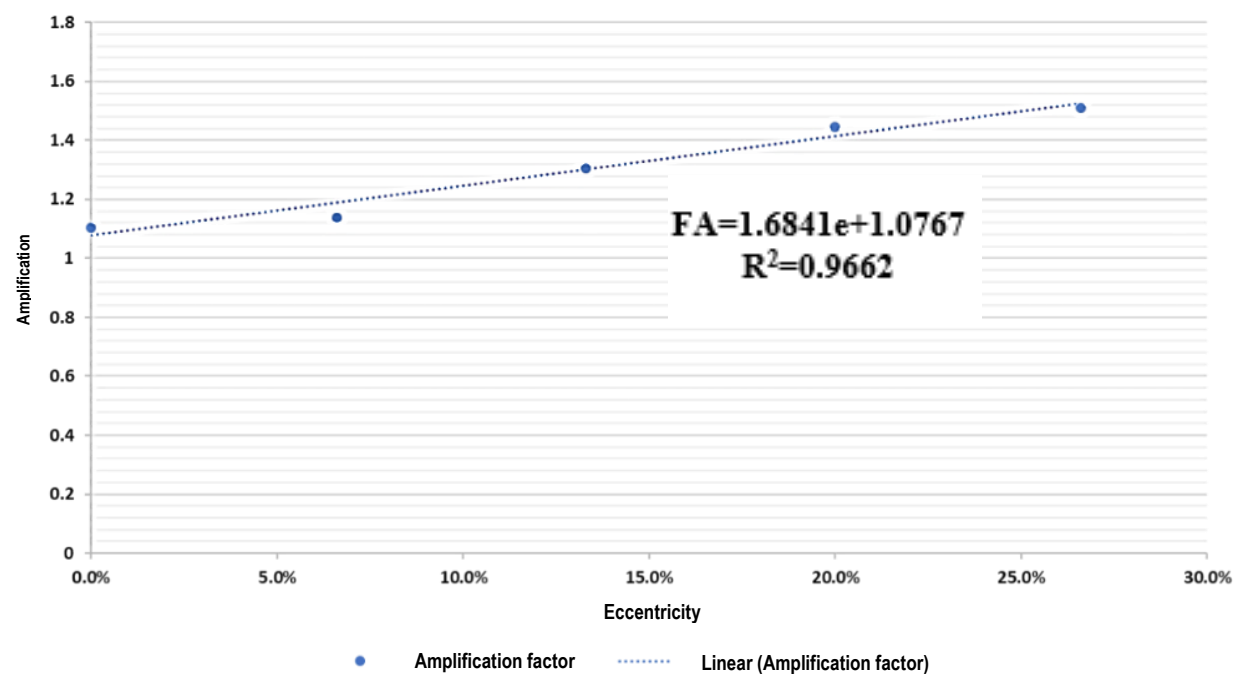

Figure 7. Rule for obtaining the amplification factor by eccentricity 


\section{RELATIONSHIP BETWEEN SPECTRAL MODAL DYNAMIC ANALYSIS AND TIME HISTORY ANALYSIS}

According to the analysis and the results obtained previously, these are related by amplification factors for the spectral modal dynamic analysis and an incidence angle for the time history analysis, which are shown below:

\subsection{When performing a spectral modal dynamic analysis:}

The Amplification Factor (FA) of the response of the structure by the bidirectionality and angles of incidence will be the greatest factor of amplification due to difference of stiffness and eccentricity:

$$
F A=m a ́ x\left(F A_{k} ; F A_{e}\right)
$$

The amplification factor for stiffness and eccentricity will be obtained from the following expressions:

$$
\begin{aligned}
& F A_{k}=0.23 k+0.87 \\
& F A_{e}=1.68 e+1.08
\end{aligned}
$$

Where:

FAk: Amplification Factor due to different stiffness in the principal directions.

FAe: Amplification Factor due to the eccentricity of the center of mass with respect to the stiffness.

k: Ratio of Global Relative Stiffness for each principal direction; $\mathrm{k}>1$.

e: Eccentricity, distance in plan of the center of mass with respect to the center of stiffness between the length of the evaluated direction.

The Global Relative Stiffness is defined as the relationship between the basal shear and the maximum displacement in a building.

The eccentricity of the building will be the one obtained from the average of eccentricities of each level, the highest average of each direction will be taken.

\subsection{When performing a dynamic time history analysis:}

Maximum responses are found with an angle of incidence equal to the direction that forms the epicenter of the earthquake considered and the accelerometric station that recorded it, as well as the direction perpendicular to it.

\section{CONCLUSIONS}

- Regular structures with different rigidities in both directions generate amplification in the seismic response due to bidirectionality and angle of incidence.

- Structures with eccentricity in the plant, generate an amplification in the seismic response due to bidirectionality and angle of incidence.

- There is a relationship between the angle of incidence and the direction that forms the accelerometric station where the earthquake and its epicentre was measured, as well as the perpendicular of this.

- There is a linear relationship, expressed in equation (2), between the amplification factor of the maximum response of the time analysis history of regular structures of different rigidities in both directions and the response of the spectral modal analysis of the same structure.

- There is a linear relationship, expressed in equation (3), between the amplification factor of the maximum response of the time analysis history of structures with plant eccentricity and the response of the spectral modal analysis of the same structure.

- According to the response of the analysis performed for the 7th structure, the effect of bidirectionality and angles of incidence does not necessarily amplify the response in irregular structures as indicated by E.030, this can be seen in that the amplification factor of this is similar to that of the 1st structure, the latter being regular in both directions.

\section{RECOMMENDATIONS}

- Analyse whitmore seismic records of other national and international accelerometric stations.

- Analyse considering the study of nonlinear properties in their different directions as well as without releasing the degrees of freedom that correspond to the torsion of the elements.

- Analyse with other heights of the building and irregularities such as soft floor, discontinuity of resistant elements, etc.

- Analyse considering synthetic records. 


\section{REFERENCES}

[1] Cruz E and Cominetti S 2000 Three - Dimensional buildings subjected to bi-directional earthquakes. Validity of analysis considering uni-directional earthquakes, 12th WCEE, Newzealand.

[2] Fernandez-Dávila I, Cominetti S and Cruz E 2000 Considering the bidirectional effects and the seismic angle variations in building design, 12th WCEE, Newzealand.

[3] Hernández J J and O López A 2003 Evaluation of combination rules for peak response calculation in three-component seismic analysis, Earthquake Engineering and Structural Dynamics, USA.

[4] López O and Torres R 1997 The critical angle of seismic incidence and the maximum structural response, Earthquake Engineering and Structural Dynamics, USA
[5] Moscoso E 2018 Efecto de la bidireccionalidad y ángulo de incidencia del sismo en la respuesta de estructuras de concreto armado, National University of Engineering, Perú

[6] Penzien J and Watabe M 1975 Characteristics of 3-Dimensional earthquake ground motions, Earthquake Engineering and Structural Dynamics, USA

[7] Salinas R and Lázares F 2003 Análisis de acelerogramas registrados en la ciudad de Lima obtenidos con la Red Acelerográfica del CISMID, XIV Congreso Nacional de Ingeniería Civil, Perú 